\title{
Review
}

\section{The politics of the human}

\author{
Anne Phillips \\ Cambridge University Press, Cambridge, 2015, viii+150 pp., ISBN: 978-1107475830
}

Contemporary Political Theory (2017) 16, 181-184. doi:10.1057/cpt.2015.74;

advance online publication 19 January 2016

This book is an expanded and revised version of four lectures delivered by Anne Phillips at the University of Cambridge during 2013. As the book's title indicates, their subject was the politics of the human, which Phillips interprets as a politics of equality. The book's main contribution to debate is the development of what its author describes as a 'claim-based account of what it is to be human' (p. 133). I thoroughly enjoyed reading it. The Politics of the Human is clear and engaging, yet also profoundly challenging and thought-provoking. In it Phillips skilfully guides her reader through a series of complex debates, some historical, mostly contemporary, including discussions of the idea of the human, questions of equality and human dignity, and posthumanism.

She begins her wide-ranging discussion by exploring competing definitions of the human, distinguishing between substantive or 'characteristics-based' versions (p. 132) and 'contentless' or 'abstract' accounts. The former, Phillips suggests in a familiar argument, 'carry exclusionary implications' (p. 33); defining the human in terms of a particular essence, properties or features effectively disqualifies some from membership in the category. Contentless notions, by contrast, divest the human of all its particularities, denying the differences or, what she refers to as the "contingencies', that individuals 'live', embodied contingencies of race, gender, skin colour and disability. In the process questions of power go missing. Against these two approaches Phillips posits her own alternative, where (echoing Rancière) claims to be human are understood as claims for equality; where, calling on her earlier work, equality is conceptualized 'through rather than despite difference' (p. 108); and in which she defines these claims (to be human and/as equal; the terms are often used interchangeably) as political not cognitive, not, that is, established in relation 'to certain facts about human beings' (p. 8), a distinction crucial to her argument.

To explore the theme of equality, Phillips engages in critical readings of the 'antifoundationalist' work of Richard Rorty and Hannah Arendt. She is particularly interested in Rorty's discussion of how those in positions of relative security might become more responsive - or sympathetic - to precaritized others in order to build

(c) 2016 Macmillan Publishers Ltd. 1470-8914 Contemporary Political Theory Vol. 16, 1, 181-184 www.palgrave.com/journals 
solidarity with them, the solidarity necessary for human rights, humanitarianism and global justice (three discourses Phillips outlines in her introduction). Her worry is that the framework underpinning Rorty's work - and arguably the three discourses just named - is one 'of what those who have and can do for those who have not and cannot' (p. 58); a framework that, she justifiably asserts, confirms rather than addresses inequalities of power.

Although critical of several elements of Arendt's work, including her view of the human condition and her overly narrow understanding of politics, Phillips draws from her the idea that equality is 'something that we establish when we treat one another as equals' (p. 69). This she immediately reformulates as 'something we bring into existence at the moment we claim it' (p. 69). Equality, she suggests later in the same chapter, is both 'claim and commitment': the commitment expressed by members of a political community 'to recognise one another as equals' and the enactment of equality 'against the odds' by those 'not currently regarded as members' (p. 78). (Interestingly, elsewhere in the book, it is the human that is described in these terms as 'claim and commitment' [p. 9]).

Three factors are particularly noteworthy about Phillips' 'claim-based' account. First, that claims (and commitments?) should not be understood as hurdles to jump 'in order to get the appropriate recognition' (p. 9); for Phillips they are a matter of politics. Second, the stress she places on the ability of subaltern populations (those 'who have not') to assert and thereby performatively enact equality via assertions of their humanity is important. It counters a certain common assumption of such groups as victims passively awaiting assistance, and it reveals what is most radical, for her, about a politics of the human, though she could perhaps have added further to this discussion by addressing what happens to human equality in circumstances where opportunities to act are foreclosed or circumscribed, as they surely are on some occasions.

Third, no one needs to qualify for equality by proving they are human. Equality rather is enacted in situations of inequality. This enactment takes the form of 'an assertion of humanness', which Phillips understands as 'simultaneous with the assertion of equality' (p. 79). There is an important proviso, however: making a claim is not necessary to be 'accepted' (p. 132) as a human or equal; indeed many never will make them and some - 'babies in arms, people in a coma' (p. 9) - cannot. To expect people to do so would turn claim-making into the kind of obstacle to equality that Phillips is arguing against. If, however, no claim is needed to establish equality or humanity, then in its absence does this mean that equality and humanity are accorded to us by others? If so, what prevents this leading to a situation where "those who have and can' act on behalf of subaltern populations, an outcome of which Phillips is rightly so critical?

Although her argument in respect of claim-making is well developed, if contestable in places, the discussion of commitment is less so. For instance, it is unclear whether the absence of a requirement to make a claim in order to be recognized as equal and human applies also to the idea of expressing a commitment to equality;

182 (C) 2016 Macmillan Publishers Ltd. 1470-8914 Contemporary Political Theory Vol. 16, 1, 181-184 
I assume it must, otherwise voicing that commitment becomes the condition for that recognition. But even after multiple readings of this text, I still cannot quite fathom what role commitment plays in the politics of the human.

Having set out her position, Phillips turns to the 'major challenge' (p. 19) posed to it by discussions of human dignity, as articulated by political theorists like Michael Rosen, Jeremy Waldron and George Kateb. Such accounts, she suggests, rest (to greater or lesser degrees) on hierarchical, 'normatively loaded' (p. 89), and/or essentialist descriptions of the human. Here Phillips addresses various examples that appear in this literature (she includes discussions of dwarf-tossing competitions, the sex trade and the sale of human organs) in order to demonstrate that what is really at issue in debates about dignity is equality. Her critique of this literature is often very persuasive; she is a sharp reader of texts. Nevertheless, I was sometimes left with questions. Phillips might be right that the language of in/equality is better able to grasp what dehumanization entails than the language of human dignity, but whether all dehumanization might be apprehensible in this way, I am less sure.

The final chapter of the book is something of a departure from the others. It tackles the issue of posthumanism. After explaining briefly why she rejects humanism (on the grounds predominantly that it steers the focus away from particularities to emphasize what is held in common), Phillips addresses three variants of posthumanism. The first, which Phillips dismisses for its tendencies to oversimplify humanism and to claim 'any significant reformulation' (p. 112) of humanism as posthumanism, she suggests, is basically a continuation of the critique of humanism without the negativities associated with anti-humanism. The second, exploring what is entailed in producing enhanced or hybrid humans (so-called posthumans, transhumans or superhumans), Phillips rejects on the grounds of equality; specifically, that genetic enhancement risks eroding 'already fragile ideas of human equality' and threatening the 'enabling material conditions' (p. 123) that underpin the commitment to it. The final variant centres on the boundaries between human/animal/machine. There are benefits, she concedes, attached to challenging anthropocentrism, particularly in discouraging what Jane Bennett calls 'species-narcissism' and encouraging an 'eco-sensibility' (Bennett cited on p. 129). Her divergence from this approach rests on the fact that it decentres the human (and human responsibility) too much, thus making its concerns irrelevant for a 'strong politics of the human' (p. 19). This rebuttal is important.

Given that The Politics of the Human is, fundamentally, about equality, I wondered at times why its author stays with the idea of the human, especially given her thoroughgoing critique of its deficiencies earlier in the book. A large part of the answer is that the language of the human is one that allows marginalized and precaritized populations to performatively enact equality. As her critique of the final strand of posthumanism reveals, however, for Phillips the category also acts in another way: as a limiter on equality claims. As she puts it: "whoever does claim to be human establishes themselves in that moment as an equal, and it is humans - not

(c) 2016 Macmillan Publishers Ltd. 1470-8914 Contemporary Political Theory Vol. 16, 1, 181-184 183 
animals or machines - who do this' (p. 132, my emphasis). In other words, it is those who are already identifiable as human (in some sense) who assert politically the humanity that is at once an assertion of equality; which demonstrates just how difficult it is to dispense entirely with cognitive definitions of the human, even in a theory that endeavours to treat both the human and equality principally as matters of politics.

Moya Lloyd Loughborough University, Loughborough LE11 3TU, UK 